\title{
Correction to: A New Normal or Business-as-Usual? Lessons for COVID-19 from Financial Crises in East and Southeast
}

\section{Asia}

\section{O. Fiona Yap ${ }^{1}$ (10}

Published online: 11 November 2020

(c) European Association of Development Research and Training Institutes (EADI) 2020

\section{Correction to: The European Journal of Development Research https://doi.org/10.1057/s41287-020-00327-3}

Due to unfortunate oversight during the Copy Editing process, the funding note has been omitted. It should be read:

Funding Research funding in part by the Research Foundation of Korea, NRF2018S1A3A2075531, Ministry of Education, the Republic of Korea, is gratefully acknowledged.

Publisher's Note Springer Nature remains neutral with regard to jurisdictional claims in published maps and institutional affiliations.

The original article can be found online at https://doi.org/10.1057/s41287-020-00327-3.

\section{O. Fiona Yap}

fiona.yap@anu.edu.au

1 The Australian National University, Canberra, ACT 2601, Australia 